\title{
Heterojunction Band Offset Limitations on Open-Circuit Voltage in p-ZnTe/n-ZnSe Solar Cells
}

\author{
A. S. Teran,
}

\author{
C. Chen, E. López, P. G. Linares, I. Artacho, A. Martí,
} and J. D. Phillips:

\begin{abstract}
Limitations on the open-circuit voltage of p-ZnTe/nZnSe heterojunction solar cells are studied via current-voltage $(I-V)$ measurements under solar concentration and at variable temperature. The open-circuit voltage reaches a maximum value of $1.95 \mathrm{~V}$ at $77 \mathrm{~K}$ and 199 suns. The open-circuit voltage shows good agreement with the calculated built-in potential of $2.00 \mathrm{~V}$ at $77 \mathrm{~K}$. These results suggest that the open-circuit voltage is limited by heterojunction band offsets associated with the type-II heterojunction band lineup, rather than the bandgap energy of the $\mathrm{ZnTe}$ absorber material.
\end{abstract}

Index Terms-Heterojunction solar cell, open-circuit voltage, zinc selenide ( $\mathrm{ZnSe}$ ), zinc telluride ( $\mathrm{ZnTe}$ ).

\section{INTRODUCTION}

$\mathbf{T}$ HE ultimate power conversion efficiency of a solar cell is limited by the current generation from solar photons and voltage provided by the energy of extracted electrons. The maximum voltage attainable for a diode solar cell (open-circuit voltage; $V_{O C}$ ) is limited to the bandgap energy $E_{G}$ of the material, where voltage is further reduced below $E_{G} / \mathrm{q}$ due to nonradiative losses, mismatch between the acceptance angle of spontaneous emission and the solid angle subtended from the sun, and energy losses from electrical contacts. Experimentally, the open-circuit voltage of a solar cell has been observed to match $E_{G} / \mathrm{q}$ when operating at low temperature under solar concentration [1]. Another mechanism for open-circuit voltage reduction is band offset in heterojunction device architectures. Heterojunctions have emerged as important in next generation solar cells in order to facilitate charge separation and collection, including organic solar cells, thin-film solar cells, and intermediate band solar cells (IBSCs). Heterojunctions also facilitate the formation of a $p-n$ junction in cases where the semiconductor of interest cannot be selectively doped n-type or p-type. $\mathrm{ZnTe}$ is an example of such a case where n-type doping is difficult to achieve due to the self-compensation from the native antisite defect $\mathrm{ZnTe}$ [2], requiring the use of heterojunctions with n-type semiconductors, such as $\mathrm{GaAs}, \mathrm{ZnO}$, and $\mathrm{ZnSe}$ with lattice mismatch $7 \%, 25 \%$, and $8 \%$, respectively [3]-[10]. All of these cases have a large lattice mismatch, resulting in the formation of threading dislocations, degrading device performance. Efficient solar cells require dislocation densities less than $10^{6} \mathrm{~cm}^{-2}$ to preserve minority carrier lifetime [11].

$\mathrm{ZnTe}$ is a promising material for solar photovoltaics, where dilute incorporation of oxygen to form $\mathrm{ZnTeO}$ alloys can provide a bulk material for intermediate band solar cells [4], [6], [7], [9], [10], [12]-[14]. Subbandgap photocurrent response due to multiphoton transitions has been demonstrated, but the voltage generated in these devices is still below expectations. So far, the highest $V_{O C}$ achieved for the $\mathrm{ZnTeO}$ solar cell is approximately $1 \mathrm{~V}$ using a p-ZnTe/n-ZnSe heterojunction [9]. The low $V_{O C}$ can be attributed to both defects in the $\mathrm{ZnTe}$ material and heterojunction band offsets. The influence of band offsets in II-VI heterojunction diodes on $V_{O C}$ needs to be understood for proper interpretation of device behavior. In order to elucidate the influence of heterojunction band offsets on voltage generation, measurements under solar concentration and low temperature may be used to reduce the influence of material defects on device behavior. In this paper, the characteristics of $\mathrm{p}-\mathrm{ZnTe} / \mathrm{n}-\mathrm{ZnSe} / \mathrm{n}-\mathrm{GaAs}$ heterojunction diodes are studied at low temperature under solar concentration, where voltage is limited by band offsets rather than the fundamental bandgap of the $\mathrm{ZnTe}$ active region of the device.

\section{EXPERIMENTAL RESULTS}

Materials were grown by molecular beam epitaxy using solid sources for $\mathrm{Zn}, \mathrm{Se}$, and Te on n-type GaAs $\left(\begin{array}{lll}0 & 0 & 1\end{array}\right)$ substrates. A nitrogen plasma source and solid source $\mathrm{ZnCl}_{2}$ were used for p-type $\mathrm{ZnTe}: \mathrm{N}$ and n-type $\mathrm{ZnSe}: \mathrm{Cl}$ doping, respectively. Solar cell devices were fabricated using conventional photolithography, metallization, and etching techniques. The device structure consists of an $\mathrm{n}-\mathrm{ZnSe}$ emitter layer, undoped $\mathrm{ZnSeTe}$ alloy intermediate layer, undoped $\mathrm{ZnTe}$ base layer, and p-ZnTe contact layer, as shown in Fig. 1. The $\mathrm{ZnSe}_{x} \mathrm{Te}_{1-x}$ alloy was graded from $x=1$ to $x=0$ over $100 \mathrm{~nm}$ with the intent of reducing dislocation density by grading the lattice constant [15]. The rate of lattice constant grading is not sufficient to achieve low dislocation density via metamorphic growth, but is necessary to achieve a reasonably abrupt electrical junction. Current-voltage $(I-V)$ measurements were conducted using a semiconductor device parameter analyzer. Solar concentration measurements were performed using a xenon flash lamp to illuminate the cells. Every point in the concentrated $I-V$ curve was obtained by 


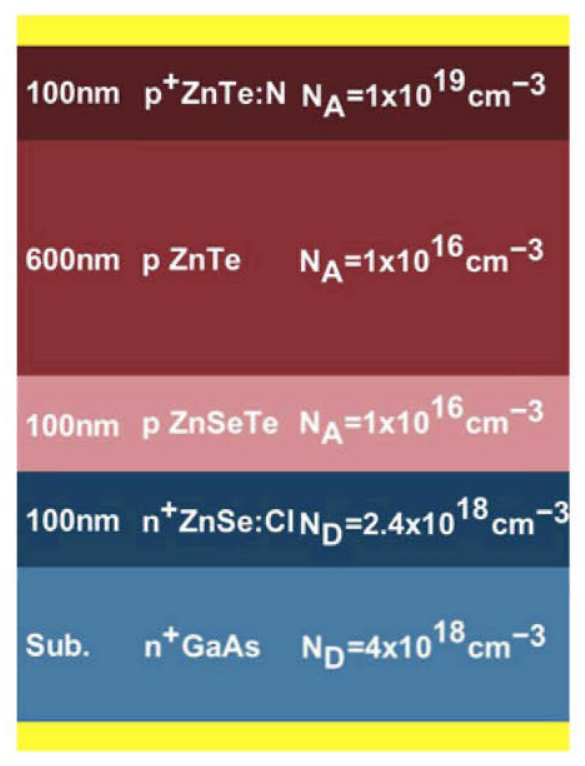

Fig. 1. Schematic drawing of the $\mathrm{p}-\mathrm{ZnTe} / \mathrm{n}-\mathrm{ZnSe}$ device structure and associated layer thicknesses and doping levels.

biasing the sample at a fixed voltage and illumination with a single flash. In order to ensure that every $I-V$ couple was obtained under the same irradiance, an $\mathrm{Si}$ detector was used to monitor the level of illumination. These measurements were carried out at temperatures ranging from room temperature to $20 \mathrm{~K}$ using a closed-cycle He cryostat. Device results were analyzed with the aid of energy band diagrams calculated numerically by finite element methods.

The current-voltage measurements under variable solar concentration and temperature are shown in Fig. 2. The short-circuit. current density $J_{S C}$ was normalized to the 1-sun $J_{S C}$ in order to facilitate the interpretation. The solar concentration values $\mathrm{X}$ were calculated by dividing the $J_{S C}$ at concentration by the $J_{S C}$ at 1 sun. The $J-V$ curves exhibit nonideal fill factors with a shunt path near $J_{S C}$ and parasitic series resistance near $V_{O C}$. This performance is consistent with past $\mathrm{Zn}$ Te diodes that suffer from series and shunt resistance [3]-[10]. The shunt path is likely due to material defects in the vicinity of the electrical junction. Series resistance is likely limited by the doping level of the n$\mathrm{ZnSe}: \mathrm{Cl}$ or electrical contact to the $\mathrm{p}-\mathrm{ZnTe}$. As expected, the influence of series resistance is more pronounced at the higher current density under solar concentration. Under solar concentration, the open-circuit voltage increases dramatically, by more than $0.5 \mathrm{~V}$ in comparison to 1 sun. This voltage increase is beyond the expected logarithmic increase of voltage with solar concentration. The large $V_{O C}$ increase under solar concentration may be attributed to the reduced influence of nonradiative processes associated with material defects under high injection levels. The open-circuit voltage increases at reduced temperatures, as shown in Fig. 3. The $V_{O C}$ increases from $1.54 \mathrm{~V}$ at $299 \mathrm{~K}$ up to $1.95 \mathrm{~V}$ at $77 \mathrm{~K}$. The $V_{O C}$ maintains a value near $1.95 \mathrm{~V}$ to around $50 \mathrm{~K}$ and then decreases at temperatures near $30 \mathrm{~K}$ and below. The reduced $V_{O C}$ at these lower temperatures may be explained by the degradation in charge carrier transport properties. At low temperatures, the increase in dislocation and

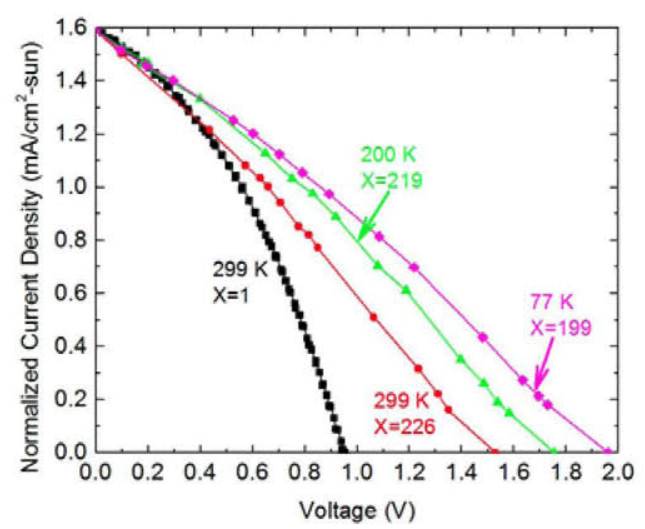

(a)

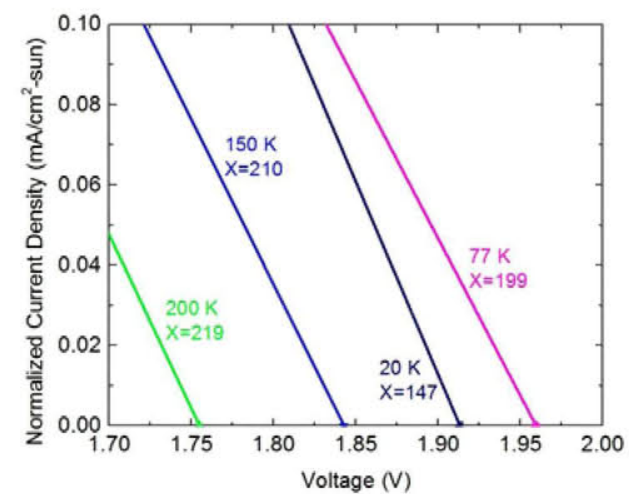

(b)

Fig. 2. (a) Normalized current density versus voltage characteristics under solar concentration and varying temperature. The solar concentration $(\mathrm{X})$ values were calculated by dividing each $J_{S C}$ by $J_{S C}^{A M 1.5}$. (b) Magnified region of the low-temperature curves near $V_{O C}$.

impurity scattering rates reduces the minority carrier mobility, which reduces the current density [16].

\section{DISCUSSION}

The temperature dependence of $V_{O C}$ can be described by the diode equation under illumination, which is given by

$$
J=J_{0} \exp \left(\frac{q V}{A k T}\right)-J_{S C}
$$

where $J_{0}$ is the reverse saturation current, $q$ is the electron charge, $k$ is the Boltzmann constant, $T$ is the temperature of the diode, and $A$ is the diode ideality factor. Equation (1) can be expanded into

$$
J=J_{00} \exp \left(-\frac{E_{A}}{A k T}\right) \exp \left(\frac{q V}{A k T}\right)-J_{S C}
$$

where $J_{00}$ is the reverse saturation current density at $T=0 \mathrm{~K}$, and $E_{A}$ is the activation energy corresponding to the energy barrier that minority carriers must overcome to generate the reverse saturation current. When operating at open circuit, (2) can be written as

$$
V_{O C}=\frac{A k T}{q} \ln \left(\frac{J_{S C}}{J_{00}}\right)+\frac{E_{A}}{q} .
$$




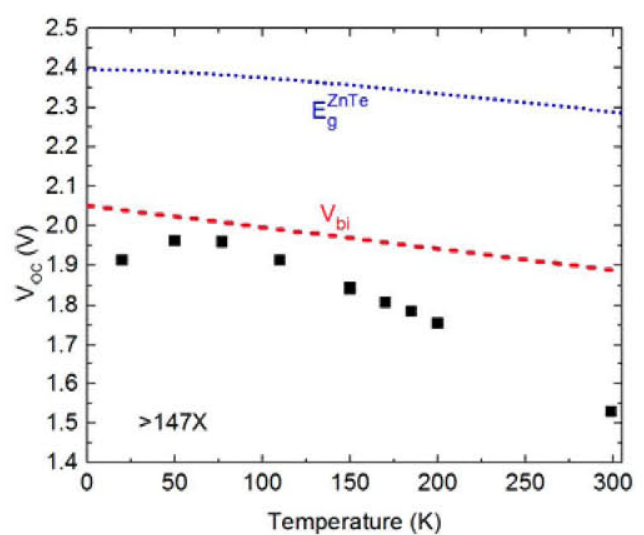

Fig. 3. Measured $V_{O C}$ versus temperature under solar concentration and comparison with the calculated values for built-in potential and $\mathrm{ZnTe}$ bandgap energy. The $V_{O C}$ limit approaches the built-in potential trend at low temperature, suggesting that the device is limited by built-in potential rather than the bandgap energy.

The voltage $V_{O C}$ is determined by the electron and hole quasiFermi level splitting, which becomes $E_{A}$ as $T$ approaches $0 \mathrm{~K}$. In an ideal homojunction solar cell, $E_{A}$ is the material bandgap $E_{G}$. In the case of heterojunction solar cells, the maximum voltage that can develop $E_{A} / \mathrm{q}$ can be limited by the conduction or valence band offset between the two semiconductor materials forming the heterojunction. The band lineup in a heterojunction will define the built-in potential in the conduction or valence band and corresponding limitation on the voltage and electron/hole quasi-Fermi level splitting.

The staggered band lineup for $\mathrm{ZnTe} / \mathrm{ZnSe}$ results in a reduced built-in potential in the conduction band for a heterojunction in comparison to a homojunction. The calculated energy band diagrams at $77 \mathrm{~K}$ under short-circuit conditions and at forward bias near flat-band conditions are shown in Fig. 4. The built-in potential at the vacuum level, which will determine $E_{A}$ and the limit for $V_{O C}$, is calculated from

$$
\begin{aligned}
q V_{b i}= & E_{g}^{\mathrm{ZnTe}}-\left(\chi^{\mathrm{ZnSe}}-\chi^{\mathrm{ZnTe}}\right) \\
& -\left(E_{f p}^{\mathrm{ZnTe}}-E_{V}^{\mathrm{ZnTe}}\right) \\
& -\left(E_{C}^{\mathrm{ZnSe}}-E_{f n}^{\mathrm{ZnSe}}\right)
\end{aligned}
$$

where $V_{b i}$ is the built-in potential, $E_{g}^{\mathrm{ZnTe}}$ is the bandgap of $\mathrm{ZnTe}$, $\chi$ is the electron affinity, $E_{f p}^{Z n T e}$ is the Fermi level on the p-ZnTe side, $E_{f n}^{\mathrm{ZnSe}}$ is the Fermi level on the n-ZnSe side, $E_{V}^{\mathrm{ZnTe}}$ is the top of the valence band on the p-ZnTe side, and $E_{C}^{Z n S e}$ is the bottom of the conduction band on the n-ZnSe side. The temperature dependence of the built-in potential and $\mathrm{ZnTe}$ bandgap is plotted in Fig. 3 using the Varshni parameters from [17] and the electron affinities for $\mathrm{ZnTe}$ and $\mathrm{ZnSe}$ from [18]. The calculated $V_{b i}$ of $2.00 \mathrm{~V}$ at $77 \mathrm{~K}$ is in strong agreement with the extracted $V_{O C}$ value of $1.95 \mathrm{~V}$ from concentration measurements. The built-in voltage, extrapolated to $0 \mathrm{~K}$, reaches a value of $2.05 \mathrm{~V}$. This built-in potential represents the upper limit of $V_{O C}$ for the $\mathrm{ZnTe} / \mathrm{ZnSe}$ heterojunction solar cell. Prior analysis of organic heterojunctions has suggested that the open-circuit voltage could in fact exceed the built-in potential for device structures where

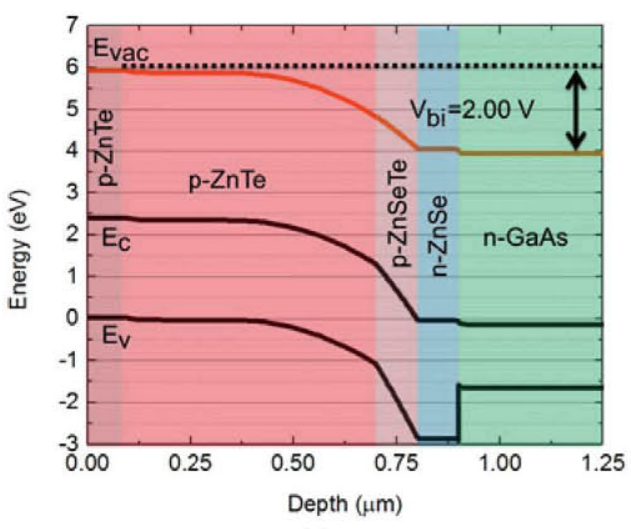

(a)

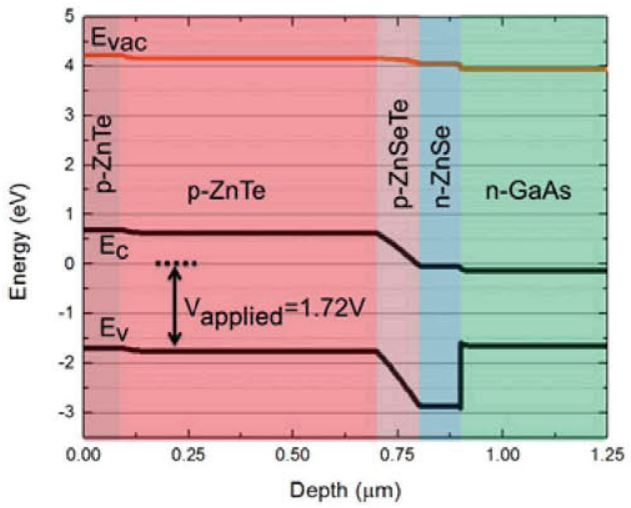

(b)

Fig. 4. Calculated energy band diagrams at $77 \mathrm{~K}$ for (a) short-circuit conditions with a built-in potential, as observed at the vacuum level of $2.00 \mathrm{~V}$ and (b) at forward bias of $1.72 \mathrm{~V}$ approaching flat-band conditions.

there is an effective force-field barrier [19]. For this to occur, band inversion would be required, and would be unlikely for the case of $\mathrm{ZnTe} / \mathrm{ZnSe}$ due to the large interface recombination loss at the heterojunction. The calculated energy band diagram under forward bias [see Fig. 4(b)] illustrates the device approaching flat-band conditions and an upper limit for $V_{O C}$. It should be noted that as simulations further approach $V_{b i} / V_{O C}$, nonphysical results, such as local minima, are observed in the potential profile and associated with the numerical methods implemented in the simulations.

\section{CONCLUSION}

In conclusion, low-temperature solar concentration measurements were performed on $\mathrm{p}-\mathrm{ZnTe} / \mathrm{n}-\mathrm{ZnSe}$ solar cells. Increased solar concentration and reduced temperatures demonstrate significant enhancement in open-circuit voltage by overcoming limitations due to nonradiative processes, providing a means to study fundamental limits of the heterojunction device behavior. The limitations on $V_{O C}$ show strong agreement with the calculated built-in potential, rather than the bandgap energy of the $\mathrm{ZnTe}$ base region. These experiments demonstrate that large $V_{O C}$ may be demonstrated in ZnTe diodes that is limited by built-in potential and underscores the importance of identifying heterojunctions with desirable energy band lineups, where low-defect density may also be achieved. 


\section{REFERENCES}

[1] P. G. Linares, A. Martí, E. Antolín, I. Ramiro, E. López, E. Hernández, D. F. Marrón, I. Artacho, I. Tobías, P. Gérard, C. Chaix, R. P. Campion, C. T. Foxon, C. R. Stanley, S. I. Molina, and A. Luque, "Extreme voltage recovery in GaAs:Ti intermediate band solar cells," Sol. Energy Mater. Sol. Cells, vol. 108, pp. 175-179, Oct. 2012.

[2] J. D. Dow, R. Hong, S. Klemm, S. Y. Ren, M. H. Tsai, O. F. Sankey, and R. V. Kasowski, "Proposed explanation of the p-type doping proclivity of ZnTe," Phys. Rev. B, vol. 43, no. 5, pp. 4396-4407, Feb. 1991.

[3] W. Wang, A. Lin, and J. D. Phillips, "Electrical characteristics and photoresponse of $\mathrm{ZnO} / \mathrm{ZnTe}$ heterojunction diodes," J. Electron. Mater, vol. 37, no. 8, pp. 1044-1048, Jun. 2008.

[4] W. Wang, A. Lin, and J. D. Phillips, "Intermediate-band photovoltaic solar cell based on ZnTe:O," Appl. Phys. Lett., vol. 95, pp. 011103-1-011103-3, Jul. 2009.

[5] W. Wang, J. D. Phillips, S. J. Kim, and X. Pan, "ZnO/ZnSe/ZnTe heterojunctions for ZnTe-based solar cells," J. Electron. Mater, vol. 40, no. 8, pp. 1674-1078, Apr. 2011.

[6] T. Tanaka, K. M. Yu, A. X. Levander, O. D. Dubon, L. A. Reichertz, N. Lopez, M. Nishio, and W. Walukiewicz, "Demonstration of $\mathrm{ZnTe}_{1-x} \mathrm{O}_{x}$ intermediate band solar cell," Jpn. J. Appl. Phys., vol. 50, pp. 082304-1-082304-3, Aug. 2011.

[7] T. Tanaka, M. Miyabara, Y. Nagao, K. Saito, Q. Guo, M. Nishio, K. M. Yu, and W. Walukiewicz, "Photocurrent induced by two-photon excitation in ZnTeO intermediate band solar cells," Appl. Phys. Lett., vol. 102, pp. 052111-1-052111-4, Feb. 2013.

[8] T. Tanaka, M. Miyabara, K. Saito, Q. Guo, M. Nishio, K. M. Yu, and W. Walukiewicz, "Development of ZnTe-based solar cells," Mater Sci. Forum, vol. 750, pp. 80-83, Mar. 2013.

[9] J. Phillips, A. Teran, C. Chen, E. Antolín, I. Ramiro, E. López, E. Hernández, I. Artacho, C. Tablero, A. Martí, and A. Luque, "Intermediate band solar energy conversion in ZnTeO," in Proc. 39th IEEE Photovoltaic Spec. Conf., 2013, pp. 1640-1643.

[10] T. Tanaka, M. Miyabara, Y. Nagao, K. Saito, Q. Guo, M. Nishio, K. M. Yu, and W. Walukiewicz, "Photogenerated current by two-step photon excitation in $\mathrm{ZnTeO}$ intermediate band solar cells with $\mathrm{n}-\mathrm{ZnO}$ window layer," IEEE J. Photovoltaics, vol. 4, no. 1, pp. 196-201, Jan. 2014.
[11] M. Yamaguchi, A. Yamamoto, and Y. Itoh, "Effect of dislocations on the efficiency of thin-film GaAs solar cells on Si substrates," J. Appl. Phys., vol. 59, no. 5, pp. 1751-1753, Mar. 1986.

[12] W. Wang, A. S. Lin, J. D. Phillips, and W. K. Metzger, "Generation and recombination rates at $\mathrm{ZnTe}: \mathrm{O}$ intermediate band states,"Appl. Phys. Lett., vol. 95, pp. 261107-1-261107-3, Dec. 2009.

[13] T. Tanaka, S. Kusaba, T. Mochinaga, K. Saito, Q. Guo, M. Nishio, K. M. Yu, and W. Walukiewicz, "Molecular beam epitaxial growth and optical properties of highly mismatched $\mathrm{ZnTe}_{1-x} \mathrm{O}_{x}$ alloys," Appl. Phys. Lett., vol. 100, pp. 011905-1-011905-3, Jan. 2012.

[14] E. Antolín, C. Chen, I. Ramiro, J. Foley, E. López, I. Artacho, J. Hwang, A. Teran, E. Hernández, C. Tablero, A. Martí, J. D. Phillips, and A. Luque, "Intermediate band to conduction band optical absorption in $\mathrm{ZnTeO}$," IEEE J. Photovoltaics, vol. 4, no. 4, pp. 1091-1094, Jul. 2014.

[15] E. A. Fitzgerald, Y. H. Xie, M. L. Green, D. Brasen, A. R. Kortan, J. Michel, Y. J. Mii, and B. E. Weir, "Totally relaxed $\mathrm{Ge}_{x} \mathrm{Si}_{1-x}$ layers with low threading dislocation densities grown on $\mathrm{Si}$ substrates," Appl. Phys. Lett., vol. 59, no. 7, pp. 811-813, Aug. 1991.

[16] J. Singh, Electronic and Optoelectronic Properties of Semiconductor Structures. Cambridge, U.K.: Cambridge University Press, 2003.

[17] R. Pässler, E. Griebl, H. Riepl, G. Lautner, S. Bauer, H. Preis, W. Gebhardt, B. Buda, D. J. As, D. Schikora, K. Lischka, K. Papagelis, and S. Ves, "Temperature dependence of exciton peak energies in $\mathrm{ZnS}, \mathrm{ZnSe}$, and ZnTe epitaxial films," J. Appl. Phys., vol. 86, no. 8, pp. 4403-4411, Oct. 1999.

[18] S. Kasap and P. Capper, Springer Handbook of Electronic and Photonic Materials. New York, NY, USA: Springer, 2007.

[19] S. J. Fonash, Solar Cell Device Physics, Burlington, MA, USA: Elsevier, 2010.

Authors' photographs and biographies not available at the time of publication. 